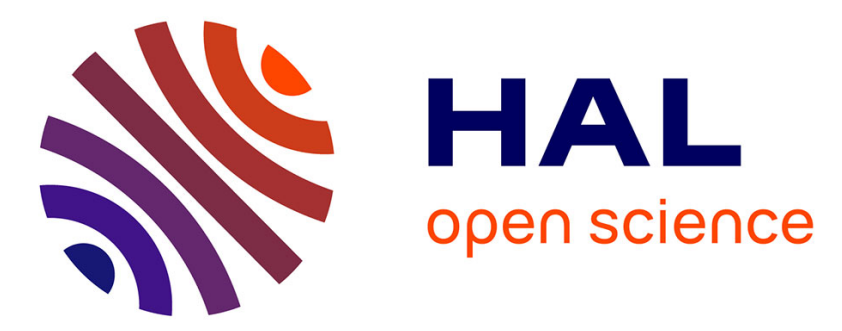

\title{
DU145 human prostate cancer cells express functional receptor activator of NFkappaB: new insights in the prostate cancer bone metastasis process.
}

Kanji Mori, Benoît Le Goff, Céline Charrier, Séverine Battaglia, Dominique Heymann, Françoise Rédini

\section{To cite this version:}

Kanji Mori, Benoît Le Goff, Céline Charrier, Séverine Battaglia, Dominique Heymann, et al.. DU145 human prostate cancer cells express functional receptor activator of NFkappaB: new insights in the prostate cancer bone metastasis process.. BONE, 2007, 40 (4), pp.981-90. 10.1016/j.bone.2006.11.006 . inserm-00667539

\section{HAL Id: inserm-00667539 https://www.hal.inserm.fr/inserm-00667539}

Submitted on 7 Feb 2012

HAL is a multi-disciplinary open access archive for the deposit and dissemination of scientific research documents, whether they are published or not. The documents may come from teaching and research institutions in France or abroad, or from public or private research centers.
L'archive ouverte pluridisciplinaire HAL, est destinée au dépôt et à la diffusion de documents scientifiques de niveau recherche, publiés ou non, émanant des établissements d'enseignement et de recherche français ou étrangers, des laboratoires publics ou privés. 
DU145 human prostate cancer cells express functional Receptor Activator of NF- $\kappa B$ :

New insights in the prostate cancer bone metastasis process.

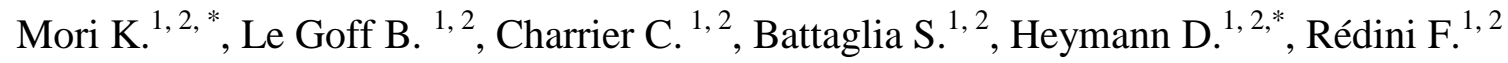

1. INSERM, ERI 7, Nantes, F-44035 France

2. Université de Nantes, Nantes atlantique universités, Laboratoire de Physiopathologie de la Résorption Osseuse et Thérapie des Tumeurs Osseuses Primitives, EA3822, Nantes, F-44035 France

\section{Correspondence and reprint request to:}

Dr. D. HEYMANN or Dr K. MORI Université de Nantes EA 3822 ; INSERM ERI 7, Physiopathologie de la Résorption Osseuse et Thérapie des Tumeurs Osseuses Primitives. Faculté de Médecine, 1 rue Gaston Veil, 44035, Nantes cedex 1, France

Tel: +33240412845

Fax: +33240412860

e-mail: dominique.heymann@univ-nantes.fr or kanchi@belle.shiga-med.ac.jp 


\section{Abstract}

Prostate cancer metastases to bone are observed in around $80 \%$ of prostate cancer patients and represent the most critical complication of advanced prostate cancer, frequently resulting in significant morbidity and mortality. As the underlying mechanisms are not fully characterized, understanding the biological mechanisms that govern prostate cancer metastases to bone at the molecular level should lead to the determination of new potential therapeutic targets. Receptor Activator of NF- $\mathrm{KB}$ ligand (RANKL)/RANK/Osteoprotegerin (OPG) are the key regulators of bone metabolism both in normal and pathological condition, including prostate cancer bone metastases. In the present study, we demonstrated that human prostate cancer cell lines, DU145 and PC3 express biologically functional RANK. Indeed, soluble human RANKL (shRANKL, 100ng/ml) treatment induced ERK 1/2, p38 and IאB phosphorylations in these cells. shRANKL administration also promoted DU145 and PC3 prostate cancer cell invasion in vitro. Whereas human OPG (hOPG) administration alone (100ng/ml) had no marked effect, combined association of both agents abolished the RANKL-induced DU145 cell invasion. As RANKL had no direct effect on DU145 cell proliferation, the observed effects were indeed related to RANKL-induced cell migration. DU145 human prostate cancer cells promoted osteoclastogenesis of osteoclast precursors generated from mouse bone marrow. Moreover, DU145 cells produced soluble factor(s) that up-regulate the proliferation of MC3T3-E1 pre-osteoblasts through the activation of the ERK 1/2 and STAT3 signal transduction pathways. 
This stimulation of pre-osteoblast proliferation resulted in an increased local RANKL expression that can activate both osteoclast/osteoclast precursors and prostate cancer cells, thus facilitating prostate cancer metastasis development in bone. We confirm that RANKL is a factor that facilitates metastasis to bone by acting as an activator of both osteoclasts and RANK-positive prostate cancer cells in our model. Furthermore, the present study provides the evidence that blocking RANKL-RANK interaction offer new therapeutic approach not only at the level of bone resorbing cells, but also by interfering with RANK-positive prostate cancer cells in the prostate cancer bone metastasis development. 
Key words: RANK, RANKL, prostate cancer, migration, bone metastasis 


\section{Introduction}

Prostate cancer is the most common malignancy diagnosed in males and is currently the major leading cause of cancer death among men [1,2]. Prostate cancer metastases to bone are observed in around $80 \%$ of prostate cancer patients and represent the most critical complication of advanced prostate cancer, frequently resulting in significant morbidity and mortality $[1,2]$. Unlike other solid tumors that are associated with osteolytic bone metastases, prostate cancer bone metastases stimulate an overall increase in both bone remodelling and bone volume [3]. In contrast, recent findings strongly suggest the importance of osteoclast function [4-9]; however the mechanisms underlining these processes are not fully determined. Therefore, understanding the biological mechanisms that govern prostate cancer metastases to bone at the molecular level and elucidation of the interactions among the factors involved should lead to the determination of new potential therapeutic targets.

Receptor activator of NF- $\mathrm{KB}$ ligand (RANKL)/RANK/Osteoprotegerin (OPG) represent the key regulators of bone metabolism both in normal and pathological condition, including prostate cancer bone metastases $[10,11]$. RANKL has been shown to both activate mature osteoclasts and mediate osteoclastogenesis in the presence of macrophage-colony stimulating factor (M-CSF) [12, 13]. RANKL is preferentially expressed on committed pre-osteoblastic cells, whereas its specific receptor RANK is expressed on hematopoietic osteoclast precursors $[14,15]$. OPG also produced by osteoblast lineage cells acts as a decoy 
receptor and inhibits osteoclast formation, function and survival by preventing the binding of RANKL to its receptor RANK [10]. Recent data strongly revealed the significant involvement of the RANKL/RANK/OPG system in metastatic bone cancer diseases, including prostate cancer bone metastases [16]. Indeed, current studies have disclosed that blocking RANKL-RANK interaction prevents the progression of prostate cancer in bone [6-9]. Furthermore, an increased expression of OPG and RANKL were reported in prostate cancer bone metastases $[17,18]$. As OPG is also a decoy receptor for TNF-related apoptosis-inducing ligand (TRAIL), it exerts inhibitory effect on TRAIL-induced cancer cell apoptosis and OPG thus represents a survival factor for prostate cancer cells [19]. RANK expressed on osteoclast/osteoclast precursors has been largely described as a key receptor that control osteoclast differentiation, activity and survival $[12,14,15,20]$. However, we and others have demonstrated the expression of functional RANK at the surface of tumor cells that develop in bone, including a mouse osteosarcoma cell line, POS-1 [21, 22]. These recent findings bring new insights in the vicious cycle theory between bone resorbing cells and cancer cells [23]. Indeed, it has been suggested that cancer cells produce soluble factors that activate directly (RANKL) or indirectly via osteoblasts (Parathyroid Hormone-related Protein, Interleukin 8...) osteoclast differentiation and maturation [24]. During the bone resorption, osteoclasts liberate growth factors stocked in the mineralized bone matrix (Insulin-like Growth Factor-1, Transforming Growth Factor- $\beta$, Fibroblast Growth Factor ...) that can further activate cancer 
cell proliferation [25]. This vicious cycle has been proposed to explain the tumor development in bone sites.

Previous studies reported that OPG expression by prostate cancer cells [8] and more recently RANK expression by cancer cells [21, 22], these all findings therefore led us to elucidate the molecular mechanisms underlying prostate cancer bone metastases and the therapeutic relevance of RANKL/RANK/OPG triad in these processes, using DU145 and PC3 human prostate cancer cell lines.

\section{Materials and Methods}

\section{Cell culture}

Human prostate cancer cell lines (DU145 and PC3) were obtained from the American Type Culture Collection (ATCC, USA). MC3T3-E1, a mouse calvaria-derived pre-osteoblast cell line was obtained from the RIKEN Cell Bank (Tsukuba, Japan). DU145 and MC3T3-E1 were cultured in Dulbecco's Modified Eagle's Medium (DMEM) (Bio Whittaker, Verviers, Belgium) and PC3 in F12 medium (Invitrogen, Eragny, France), respectively supplemented with $10 \%$ fetal bovine serum (FBS, Hyclone, France), at $37^{\circ} \mathrm{C}$ in a humidified atmosphere $\left(5 \% \mathrm{CO}_{2} / 95 \%\right.$ air $)$.

\section{Characterization of human prostate cancer cell lines}


- RNA extraction and RT-PCR analysis

Total RNA was extracted from human prostate cancer cell lines using TRIzol reagent (Invitrogen) following manufacturer's recommendation. First, RNA $(5 \mu \mathrm{g})$ was reverse

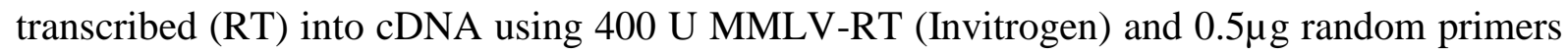
(Promega, Madison, USA). Two microliters of the RT products were subjected to PCR using 1.25 U of Ampli Taq Gold (Applied Biosystems, Foster City, USA) and upstream and downstream primers (20pmol each) to determine the expression of human OPG (hOPG) [5'-gctaacctcaccttcgag-3' (sense), 5'-tgattggacctggttacc-3' (anti-sense)], human RANK (hRANK) [5'-ttaagccagtgcttcacggg-3' (sense), 5'-acgtagaccacgatgatgtcgc-3' (anti-sense)], human RANKL (hRANKL) [5'-gccagtgggagatgttag-3' (sense), 5'-ttagctgcaagttttccc-3' (anti-sense)], human interleukin (hIL)-6 [5'-aaagaggcactggcagaaaa-3' (sense), 5'-aaagctgcgcagaatgagat-3' (anti-sense)], hIL-11 [5'-ctgagcctgtggccagata-3' (sense), 5'-gcccagtcaagtgtcaggtg-3' (anti-sense)], human oncostatin $\mathrm{M} \quad$ (hOSM) [5'-ataggcagctgctcgaaaga-3' (sense), 5' -actgagtgcatgaagcgatg-3' (anti-sense)], human leukemia inhibitory factor (hLIF) [5'-accagatcaggagccaactg- 3 , (sense), 5'-gttgacagcccagcttcttc-3' (anti-sense)] and 18S [5'-tcaagaacgaaagtcggaggtc-3' (sense), 5'-ttattgctcaatctcgggtggct-3' (anti-sense)]. The thermal cycle profile was as follows: denaturation for 30 seconds at $95^{\circ} \mathrm{C}$, annealing for 30 seconds at $58^{\circ} \mathrm{C}$ (hRANKL), $60^{\circ} \mathrm{C}$ (hOPG) and $62^{\circ} \mathrm{C}$ (hIL-6, hIL-11, hOSM, hLIF and 18S) respectively, or 4 minutes at $68^{\circ} \mathrm{C}$ 
(hRANK), and extension for 60 seconds at $72^{\circ} \mathrm{C}$. After the number of PCR cycles was increased, a plot was done for each sample and the cycle values corresponding to the linear part of the amplification curve were determined and used to quantify the messages versus the $18 \mathrm{~S}$ signal determined in the same way. The cycle number used was 40 cycles for hRANK, hRANKL, hOPG, hIL-11, and hOSM, 35 cycles for hIL-6 and hLIF, and 20 cycles for 18S, respectively. The PCR products were electrophoresed on 1\% agarose gel containing ethidium bromide. The mRNA levels of each gene were standardized to $18 \mathrm{~S}$ levels.

\section{- Immunocytochemistry}

The analysis of RANK expression at the protein level on prostate cancer cells was performed by cytospin preparation and immunocytochemistry staining. After trypsin treatment, cells were suspended in phosphate buffered saline (PBS, Bio Whittaker) at $400 \times 10^{3}$ cells $/ \mathrm{ml}$, centrifuged for 4 minutes at $600 \mathrm{rpm}$ on glass slides (Cytocentrifugeuse Shandon Cytospin 3, Thermo Electron Corporation, France) and fixed by acetone. The cytospin slides were then stained by immunocytochemistry. Endogenous peroxidase activity was blocked using $3 \% \mathrm{H}_{2} \mathrm{O}_{2}$ in distilled water, then the slides were incubated with a human anti-RANK monoclonal antibody (1:5 dilution, Santa Cruz Biotechnology, CA, USA) overnight at $4^{\circ} \mathrm{C}$, then with a biotin-labelled secondary antibody (1:200 dilution, Rockland immunohistochemicals Inc., Gilbertsville, PA, USA). Cytospin slides were then subjected to avidin-conjugated peroxidase 
(Sigma-Aldrich, St. Louis, MO, USA). Finally, peroxidase activity was detected using a commercially available kit (AEC staining kit, Sigma-Aldrich), and the sections were counterstained with hematoxylin. Negative control slides were prepared by incubating sections with PBS instead of the primary antibody.

\section{Signal transduction analyses by Western Blot}

DU145 and PC3 cells were grown in a 6-multiwell plate until 70-80\% of confluence in their respective growth medium. Then, DU145 and PC3 cells were washed three times with their respective culture medium and cultured in serum-free respective culture medium for 24 hours before being incubated for 2, 5, 10, 15, 30,60 and 120 minutes in the absence or presence of 100ng/ml soluble hRANKL (shRANKL, kindly provided by Amgen Inc., Thousand Oaks, USA). Both cells were then lysed in ice-cold buffer $(\mathrm{NaCl} 150 \mathrm{mM}$, Tris $50 \mathrm{mM}$, Nonidet P-40 $1 \%$, sodium deoxycholate $0.25 \%, \mathrm{NaF} 1 \mathrm{mM}, \mathrm{NaVO}_{4} 1 \mathrm{mM}$, leupeptine $10 \mathrm{mg} / \mathrm{ml}$, aprotinin $10 \mathrm{mg} / \mathrm{ml}$, PMSF $0.5 \mathrm{mM}$ ). Total amount of proteins was determined in each sample using a bicinchominic acid (BCA, Sigma) based procedure. Briefly, 10 $\mu$ l of cellular lysis or standard bovine serum albumin (BSA) solution were added to $200 \mu 1$ of reagent (Copper II solution 1/50 diluted in bicinchominic acid) and incubated for 30 minutes at $37^{\circ} \mathrm{C}$. Optic density (OD) was determined at $570 \mathrm{~nm}$ as well as the protein concentration compared to the standard curve using a Wallac 1420 VICTOR 2 TM multilabel counter (Perkin Elmer, MA, USA). The same amounts 
of proteins were resolved on $10 \%$ SDS-polyacrylamide gel electrophoresis (PAGE), and transferred to a poly vinydilene fluorure (PVDF) membrane (Millipore, Bedford, MA, USA). The levels of phosphorylated forms of ERK 1/2 (Thr202/Tyr204), p38 (Thr180/Tyr182), IkB (Ser32) (Cell Signaling Technologies, Beverly, MA, USA), and total forms of ERK 1/2 (Cell Signaling Technologies), p38 (R\&D systems, MN, USA), IкB (Tebu-bio, Le Perray en Yvelines, France) were detected by respective specific antibodies (Ozyme, Saint-Quentin en Yvelines, France) in PBS, $0.05 \%$ Tween 20, 3\% BSA, and revealed using the BM Chemiluminescence Western Blotting Substrate (Roche Applied Science, IN, USA).

\section{Migration analyses by slit assay}

DU145 and PC3 cells were seeded at the density of $40 \times 10^{3}$ cells per well into a 24-multiwell plate, and cultured in their respective culture medium supplemented with $1 \%$ FBS. At the time of confluence, both cells were incubated in the absence or presence of shRANKL (5 and 100ng/ml) for 24 hours. Then, a slit was made horizontally with a white tip at the centre of each confluent well, the medium was changed after gentle rinse and cells were cultured for 24 hours with or without shRANKL (5 and 100ng/ml). hOPG (kindly provided by Amgen Inc., 100ng/ml) alone or combined by pre-incubation with shRANKL (shRANKL:hOPG ratio of 1:5) were used in the same manner. Cell invasion on the slit of the confluent well was assessed in each condition by light microscopy. The effect of a MEK/ERK inhibitor (UO126, 10 $\mu \mathrm{M})$, a 
p38 inhibitor $(\mathrm{SB} 203580,10 \mu \mathrm{M})$ and a NF- $\mathrm{\kappa B}$ translocation inhibitor $(\mathrm{SN} 50,18 \mu \mathrm{M})$

(Calbiochem, CA, USA) were tested in the same experimental conditions. These inhibitors were added 2 hours before the incubation with shRANKL or hOPG and maintained during the culture period at the indicated concentration.

\section{Time lapse assay}

DU145 cells were seeded at the density of $40 \times 10^{3}$ cells per well into a 6-multiwell plate, and cultured in DMEM supplemented with $1 \% \mathrm{FBS}$, in the absence or presence of 100ng/ml shRANKL. Phase-contrast photographs (Leica, Germany) were taken every 10 minutes during 24 hours and edited using the Metamorph software. The number of cell divisions was then manually counted and the percentage of cell division was determined according to the following formula: number of cell division/original cell number $\mathrm{x} 100(\%)$. To control DU145 cell invasion, a slit assay was performed as previously described using a 6-multiwell plate and DU145 cells invasion on the slit was monitored during 24 hours (Leica). To measure the magnitude of RANKL-induced cell invasion on the slit, each slit was divided into three sections and the cell invasion of each section was determined during 24 hours. The total invaded areas of the three sections were statistically compared between each group.

\section{Cell proliferation assays}


DU145 cells were seeded at the density of $2 \times 10^{3}$ cells per well into a 96-multiwell plate, and cultured for 72 hours in DMEM supplemented with $0.5 \%$ FBS in the absence or presence of shRANKL $(5,50,100 \mathrm{ng} / \mathrm{ml})$. The medium was changed every 24 hours and the cell proliferation was determined by a XTT based method, using Cell Proliferation Kit II (Sigma)

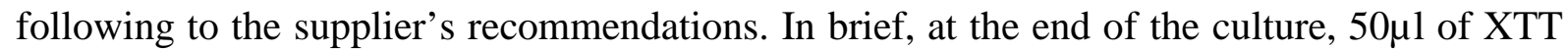
reagent were added in each well, and incubated 6 hours at $37^{\circ} \mathrm{C}$. Then, OD was determined at $450 \mathrm{~nm}$ using a Wallac 1420 VICTOR 2 TM multilabel counter.

\section{- Trypan blue exclusion}

Trypan blue exclusion was used to quantify the viable cells. DU145 cells were seeded into a 24-multiwell plate $\left(5 \times 10^{3}\right.$ cells/well) and cultured in DMEM supplemented with 0.5 to $10 \%$ FBS in the absence or presence of $100 \mathrm{ng} / \mathrm{ml}$ shRANKL, then the viable cell number was counted at day 1,4 and 7.

\section{Human prostate cancer cell effects on bone cells}

\section{- Conditioned medium (CM)}

DU145 cells $\left(10^{4}\right.$ cells $\left./ \mathrm{cm}^{2}\right)$ were grown in a $25 \mathrm{~cm}^{2}$ flask until reaching $70-80 \%$ confluence in DMEM supplemented with 10\% FBS. Then, cells were washed three times with PBS and the 
medium was changed to serum-free DMEM in the presence or absence of 100ng/ml shRANKL.

After 24 hours, conditioned medium (CM) was collected and centrifuged at 1000rpm for 10 minutes and stored at $-80^{\circ} \mathrm{C}$ until use. The same volume of serum-free DMEM incubated in the same conditions without cells was used as a control CM (CT CM).

\section{- Osteoclastogenesis}

Osteoclast precursors were generated from 4-5 weeks-old swiss male mice (Janvier, Le Genest Saint Isle, France). Briefly, bone marrow cells isolated from mice tibiae and femora were suspended in $\alpha$-MEM (Invitrogen) supplemented with 10\% FBS and 1\% non-essential amino acid (NEAA) (Invitrogen) and cultured in the presence of $5 \mathrm{ng} / \mathrm{ml}$ mouse M-CSF (R\&D systems). After 24 hours, non-adherent cells were collected and used as osteoclast precursors. They were seeded into a 24 -multiwell plate $\left(10^{6}\right.$ cells/well $)$ in $\alpha$-MEM supplemented with $10 \%$ FBS and $1 \%$ NEAA in the presence or absence of $100 \mathrm{ng} / \mathrm{ml}$ shRANKL, $12 \mathrm{ng} / \mathrm{ml}$ mouse M-CSF, with or without DU145 cells $\left(10^{3}\right.$ cells/well). Direct or separate co-cultures were performed using 24 well format-culture chambers (Cell Culture Insert, BD Falcon, NJ, USA). Half of medium was changed every 72 hours. After 7 days, cells were fixed and stained for tartrate-resistant acid phosphatase (TRAP) using Acid Phosphatase kit (Sigma-Aldrich) following the manufacturer's recommendation, and the number of TRAP-positive multinucleated cells (> 3 nuclei) were counted by light microscopy. To identify the RANKL 
effect through RANK-positive DU145 cells, increased concentration of shRANKL (200ng/ml) was also tested in the same experimental condition.

\section{- Pre-osteoblast cell proliferation assay}

The mouse pre-osteoblast MC3T3-E1 cells were seeded into a 96-multiwell plate (2.8 x $10^{3}$ cells/well) and cultured for 72 hours in CT CM or CM from DU145 cells incubated with or without $100 \mathrm{ng} / \mathrm{ml}$ shRANKL supplemented with $5 \%$ FBS. The medium was changed every 48 hours and the cell proliferation was determined using a XTT based method as described above. As an additional experiment, MC3T3-E1 cells were cultured with or without suramin $(50-500 \mu \mathrm{g} / \mathrm{ml}$, Sigma), a pan growth factor blocker. MC3T3-E1 cell proliferation was measured by direct cell counting using the trypan blue exclusion method, as suramin interferes with cell proliferation assays based on mitochondrial enzyme activity [26]. Further, to determine which soluble factor mainly involves in MC3T3-E1 cell proliferation induced by CM from DU145, neutralizing inhibitors were tested. According to the results of RT-PCR and western blot, we have tested anti-mouse IL-6 receptor antibody $(10 \mu \mathrm{g} / \mathrm{ml})$ and anti-human LIF antibody $(10 \mu \mathrm{g} / \mathrm{ml})$ (R\&D systems). Anti-goat $\operatorname{IgG}(10 \mu \mathrm{g} / \mathrm{ml}, \mathrm{R} \& \mathrm{D}$ systems) was used as negative control. These antibodies were pre-incubated with MC3T3-E1 cells or CM from DU145 according to the antibodies for 1 hour before the experiment and maintained during the culture period at the indicated concentration. 
- Signal transduction analyses by Western Blot

MC3T3-E1 cells were seeded $\left(10^{4}\right.$ cells $\left./ \mathrm{cm}^{2}\right)$ into a 6-multiwell plate in DMEM supplemented with $10 \%$ FBS. At 70-80\% of confluence, MC3T3-E1 cells were washed three times with DMEM, cultured in serum-free DMEM for 24 hours, and then the cells were incubated for 30 minutes with CT CM. MC3T3-E1 cells were then incubated for 2, 5, 10, 15 and 30 minutes in the presence or absence of CM from DU145 cells. After the treatments, cell lysates were prepared as described above ( $\S$ signal transduction analyses) and subjected to western blot analyses. The induction of the phosphorylated forms of ERK 1/2 (Thr202/Tyr204), p38 (Thr180/Tyr182), signal transducer and activator of transduction (STAT)1 (Tyr701), STAT3 (Tyr705) (Cell Signaling Technologies), STAT5 (ZYMED Laboratories, Invitrogen immunodetection, San Francisco, CA, USA) and Akt (Ser473) (Cell Signaling Technologies) were determined as well as total forms of ERK 1/2 (Cell Signaling Technologies), p38 (R\&D systems), STAT1, STAT3, STAT5 (BD Biosciences, CA, USA) and Akt (Cell Signaling Technologies).

- Alkaline Phosphatase (ALP) activity

Alkaline phosphatase (ALP) activity was determined in MC3T3-E1 cells as previously reported [27] with slight modifications. Briefly, MC3T3-E1 cells were seeded into a 
24-multiwell plate $\left(5 \times 10^{3}\right.$ cells/well) and cultured for 7 days in CT CM or CM from DU145 cells supplemented with 5\% FBS and 50 $\mathrm{g} / \mathrm{ml}$ ascorbic acid (Sigma). At the end of the culture period, cells were lysed in ice-cold buffer $[\mathrm{NaCl} 150 \mathrm{mM}$, Tris $50 \mathrm{mM}$, Nonidet P-40 1\%, sodium deoxycholate $0.25 \%$, NaF $1 \mathrm{mM}$, leupeptine $10 \mathrm{mg} / \mathrm{ml}$, aprotinin $10 \mathrm{mg} / \mathrm{ml}$, PMSF 0.5mM]. ALP activity was determined by Enzyline PAL kit (BioMérieux, Marcy l'Etoile, France) according to the supplier's recommendations.

\section{- Mineralization assay}

Alizarin red-S staining was used to detect the mineralized nodule formation in vitro as previously reported [27] with slight modifications. Briefly, mouse bone marrow cells were cultured in the absence or presence of DU145 cells for 14 days in $\alpha-$ MEM containing $10^{-8} \mathrm{M}$ dexamethasone (Sigma), 50 $\mu \mathrm{g} / \mathrm{ml}$ ascorbic acid (Sigma) and 10mM Na- $\beta$-glycerophosphate (Sigma) was also added for the last 7 days of the culture. Adherent cells were washed with PBS, and then fixed in ice-cold $70 \%$ ethanol for 1 hour. The fixed cells were washed with distilled water and incubated with alizarin red-S (Merck KGaA, Darmstadt, Germany, 40mM, pH 7.4) for 10 minutes at room temperature. After extensive washing, the presence of mineralized nodes was revealed by light microscopy.

\section{Statistical analysis}


Represented data are the results of three independent studies at least. Mann-Whitney's

$U$ test was used to assess differences in experimental groups. $P$ values less than 0.05 were considered statistically significant.

\section{Results}

Human prostate cancer cell lines DU145 and PC3 express RANK and OPG

The expression of the molecular triad RANKL/RANK/OPG was analysed in both DU145 and PC3 human prostate cancer cell lines. RT-PCR analyses revealed that both cell lines were positive for RANK and OPG but negative for RANKL at the transcript level (Figure 1). We further analyzed major cytokines expressions that involving tumor-bone cells cross-talks through STAT3 signal transduction pathway. Both cell lines were positive for IL-6 and LIF; however negative for IL-11 and OSM at the transcript level (Figure 1). Immunocytochemical analyses confirmed the positive RANK expression at the protein level in DU145 and PC3 human prostate cancer cell lines, mainly at the cell membrane level (Figure 2).

RANKL induces ERK 1/2, p38 and IKB phosphorylation in RANK-expressing prostate cancer cells 
As RANK expression was confirmed at the protein level, we further studied its functionality by western blot which signalling pathways were activated when RANK-positive prostate cancer cells were incubated with 100ng/ml shRANKL. Represented results in Figure $3 \mathrm{~A}$ showed an acute activation of ERK 1/2, p38 and I $\kappa$ B phosphorylation respectively after 5, 2 and 15 minutes incubation as compared to the corresponding total forms in DU145 cells. shRANKL treatment (100ng/ml) also induced acute activation of ERK 1/2 phosphorylation in PC3 cells after 2 minutes incubation; however the magnitude was lower than that of in DU145 cells (Figure 3B). These results revealed that RANKL is able to activate signal transduction pathways in RANK-expressing prostate cancer cells as well as its receptor (RANK) on these cells is functional.

\section{RANKL stimulates DU145 and PC3 cell migration}

In a second set of experiments, we studied whether RANKL could induce biological activity in RANK-positive prostate cancer cells, DU145 and PC3. Migration experiments showed that shRANKL treatment significantly promoted DU145 cell invasion on the slit made in the DU145 confluent well compared to that of the control group in a dose-dependent manner (Figures $4 \mathrm{~A}, \mathrm{~b}$ and $\mathrm{c}$ compared to a). Whereas treatment with $100 \mathrm{ng} / \mathrm{ml}$ hOPG alone has no marked effect on cell invasion (Figure 4A, d compared to a), the combined association of hOPG with shRANKL at a shRANKL:hOPG ratio of 1:5 (pre-incubated) abolished the 
shRANKL-induced cell invasion on the slit (Figure 4A, e). Several inhibitors of signal transduction pathways were then used to determine which pathway was involved in this effect. Among the specific inhibitors tested, only UO126, a MEK/ERK inhibitor partially inhibited RANKL-induced cell invasion (Figure 4A, g compared to f), whereas other inhibitors tested showed no significant effects (data not shown). shRANKL treatment also induce PC3 cell invasion on the slit made in the PC3 confluent well compared to the control group (Figure 4A, $\mathrm{i}$ compared to h); however DU145 cells were more sensitive for RANKL treatment. Thus, further analyses were performed using DU145 cells. The invasion magnitude was further quantified by slit time lapse assay using DU145 cells. The areas of the slit invaded during 24 hours by DU145 cells were significantly increased in the presence of $100 \mathrm{ng} / \mathrm{ml}$ shRANKL compared to the control group (respectively $1.19 \times 10^{5} \pm 0.135 \times 10^{5} \mu \mathrm{m}^{2}$ and $1.04 \times 10^{5} \pm 0.0588 \times 10^{5} \mu \mathrm{m}^{2}, \mathrm{p}=0.02$, Figure 4B).

\section{RANKL does not influence DU145 cell proliferation}

Additional experiments were performed to see whether RANKL-induced stimulation of DU145 cell invasion could be the consequence of an up-regulated cell proliferation. Neither XTT assay nor manual cell counting could demonstrate any significant difference of DU145 cell proliferation after shRANKL treatment $(100 \mathrm{ng} / \mathrm{ml})$. These results were corroborated by the 
absence of significant difference in the percentage of cell division quantified by the time lapse assay $(50.3 \%$ vs $52.4 \%, \mathrm{p}=0.56)$.

\section{DU145 cells produce soluble factor(s) that stimulate osteoclastogenesis}

Co-cultures of DU145 cells with osteoclast precursors generated from mouse bone marrow cells were used to analyse the influence of prostate cancer cells on osteoclastogenesis. We demonstrated that DU145 prostate cancer cells up-regulated osteoclastogenesis around $20 \%$ despite the presence of culture chambers or not $(\mathrm{p}<0.05)$ (Figure 5). The similar results observed with direct contact or separate co-culture in chambers revealed that cell-cell contact is not necessary for osteoclastogenesis induced by DU145 cells. The induction of multinucleated osteoclasts was not observed in the absence of shRANKL even the TRAP-positive mononuclear cells were scarcely observed. Increased shRANKL treatment $(200 \mathrm{ng} / \mathrm{ml})$ has same effect of DU145 cell-induced osteoclastogenesis compared to $100 \mathrm{ng} / \mathrm{ml}$ shRANKL treatment (Figure 5).

\section{DU145 effects on the MC3T3-E1 mouse pre-osteoblastic cell line}

- Soluble factor(s) produced by DU145 cells stimulate MC3T3-E1 cell proliferation

When CM from DU145 cells was added to MC3T3-E1 cells, it induced a significant up-regulation of pre-osteoblastic cell proliferation by more than $100 \%(\mathrm{p}<0.001$, Figure $6 \mathrm{~A})$. 
CM from DU145 cells incubated with shRANKL has similar effect on MC3T3-E1 cell proliferation (Figure 6A). Suramin, a pan-growth factor blocker, significantly abrogated the stimulation of MC3T3-E1 cell proliferation induced by CM from DU145 cells in a dose-dependent manner (Figure 6B). These results demonstrated that prostate cancer cells produce growth factor(s) that are able to stimulate the pre-osteoblast cell proliferation. Among neutralizing inhibitors used, anti-mouse IL-6 receptor antibody partially abrogated CM from DU145-induced MC3T3-E1 cell proliferation (Figure 6C).

- Conditioned medium from DU145 cells activates the ERK 1/2 and STAT3 signal transduction pathways in pre-osteoblast cells

We further studied which signal transduction pathways were activated in the DU145 cell-induced stimulation of pre-osteoblast cells proliferation. When MC3T3-E1 cells were incubated in the presence of CM from DU145 cells, a huge activation of ERK 1/2 and STAT3 phosphorylations were observed after 2 and 15 minutes, respectively (Figure 7).

- Conditioned medium from DU145 cells does not modulate ALP activity and mineralized nodule formation in pre-osteoblasts

To see whether soluble factor(s) produced by DU145 prostate cancer cells can modulate osteoblast activity, ALP activity and mineralization assays were studied in 
MC3T3-E1 cells. CM from DU145 cells treatment modified neither ALP activity nor mineralized nodule formation in MC3T3-E1 cells (data not shown).

These overall data demonstrated that DU145 human prostate cancer cells are able to modulate bone cells behaviour by inducing osteoclastogenesis and stimulating pre-osteoblast proliferation through the activation of ERK 1/2 and STAT3 signal transduction pathways.

\section{Discussion}

The present study was designed to better characterize the involvement of the RANKL-RANK axis in the regulation of bone cells-prostate cancer cells interactions. First, we demonstrated the functional RANK expression at the surface of DU145 and PC3 human prostate cancer cells. The functionality of this receptor was further evidenced as the shRANKL administration promoted human prostate cancer cell invasion in vitro, which was the result of the increased cell migration rather than the increased cell proliferation.

Second, we demonstrated that DU145 cells produced soluble factor(s) that act on cells in bone microenvironment by enhancing mouse pre-osteoblast cell proliferation and inducing osteoclastogenesis. These overall results clearly demonstrate the complex cross-talks between bone cells and cancer cells during prostate tumor development in bone.

Because DU145 cells have shown better response to RANKL treatment compared to PC3 cells (signal transduction analysis and migration assay), we performed further analyses using DU145 cells. DU145 cells were known to brain metastatic cell line; however an in vivo model of prostate cancer growth in bone by intratibial inoculation of DU145 cells has been 
established [28]. In this model, an increase in number of osteoclasts cells was observed similar to PC3 cell model; it is therefore rational to analyze prostate cancer cells-bone cells interaction using this cell line.

RANK expressed at the surface of osteoclasts is the essential signalling receptor for osteoclast differentiation $[12,14,15,20]$. However its expression is not restricted to this cell type, as it was also observed in other tissue including mammary gland [29], lung [20], brain [20], kidney [20] and hypertrophic chondrocytes [15]. Recently, functional RANK expression on tumor cells was reported by our laboratory [21] and others [22, 30]. Indeed, we have recently reported the expression of functional RANK in POS-1 mouse osteosarcoma cells [21]. In these RANK-expressing cells, RANKL induced the expression of BMP-2 and slightly inhibited osteosarcoma cell proliferation [21]. Moreover, RANK expression was confirmed in other osteosarcoma cell lines from human origin (MG63, Saos-2 and MNNG-HOS) together with some human osteosarcoma specimens in both at the transcript and protein levels (Mori K et al. submitted). In addition, Jones et al. have more recently reported the expression of functional RANK on human breast cancer (MDA-MB231, Hs578T, MCF7), human prostate cancer (LNCaP, DU145) and mouse melanoma (B16F10) cell lines [30]. As we demonstrated RANKL-induced RANK-positive DU145 cell migration in the present study, Jones et al. also observed RANKL-triggered migration of RANK-expressing human epithelial cancer cells and melanoma cells. 
The biological functionality of RANK has been also revealed through the activation including ERK 1/2, p38 and IאB pathways, the most reported pathways in the literature [31], in response to RANKL. However, the result of RANKL-induced migration of DU145 cells is only partially mediated by the MEK/ERK pathway suggesting the involvement of other down stream signalling pathways that remain to be determined.

Although both DU145 and PC3 human prostate cancer cells did not express RANKL at the transcript level in our in vitro condition, RANKL is abundant in bone environment, thus being able to bind to RANK expressed on prostate cancer cells in a paracrine (soluble RANKL) and/or juxtacrine (membranous RANKL) manner. Therefore, RANKL has two potential targets in this tumoral bone environment (Figure 8): one is osteoclasts/osteoclast precursors and the other is RANK-positive prostate cancer cells. RANKL through its binding to RANK expressed on osteoclast/osteoclast precursors increases osteoclastic activity leading to bone degradation that allows the release of tumor-supportive growth factors stocked in the bone matrix. These factors stimulate the vicious cycle that takes place between osteolytic process and tumor development in bone site [32]. The bone degradation may also provide enough space for subsequent RANK-positive prostate cancer cell migration enhanced by RANKL. Thus, RANK expressed on both osteoclasts and prostate cancer cells in tumoral bone microenvironment has a propensity for prostate cancer bone metastasis development by synergic effect. Indeed, despite 
its overall osteoblastic profile, recent evidences suggested the significant involvement of osteolytic lesion preceding osteoblastic prostate cancer bone metastasis development [4-9].

The RANKL/RANK/OPG triad represents the key regulator of bone metabolism in both normal and pathological condition [10]. Recent findings strongly suggested the significant involvement of this triad as therapeutic targets in prostate cancer bone metastasis $[6-9,11,30]$. Indeed, it has been reported that two cytokines, OPG and soluble RANK (sRANK)-Fc blocked RANKL activity and significantly diminished prostate cancer progression in bone tissue $[6,7$, 9]. In these studies, the effect of such cytokines is indirect on tumor progression as OPG or sRANK-Fc did not exert direct effect on tumor growth and viability in vitro. Moreover, Zhang et al. failed to demonstrate OPG-/sRANK-Fc-induced tumor cell growth inhibition in non-osseous tissue (subcutaneous) in vivo $[6,7]$. These results suggested that the tumor cell growth inhibition induced by OPG or sRANK-Fc was mediated via the bone microenvironment rather than the direct effect on tumor cells $[6,7]$. The results of the present study provide the evidence that RANKL can directly affects RANK-positive prostate cancer cells by inducing their migration. To reveal visible RANKL-induced prostate cancer cell migration, it is necessary to provide enough space where they can migrate. In bone tissue, RANKL can activate osteoclasts/osteoclast precursors that initiate bone degradation, providing such space for tumor cell migration. Thus, the previously reported OPG-/sRANK-Fc-induced tumor growth inhibition might be partially due to the direct effect on the RANK-positive prostate cancer cells 
by reducing RANKL-induced tumor cell migration. Therefore, a therapeutic approach using exogenous OPG or sRANK-Fc administration may be suggested even if they don't affect cell proliferation or survival, because these agents could inhibit tumor cell migration. This effect could be additional to the direct inhibition of bone resorption, leading to a resultant decrease of tumor growth.

Alternatively, we investigated the role of prostate cancer cells on osteoclast and osteoblast cells. Using osteoclast precursors generated from mouse bone marrow cells, we demonstrated that DU145 cells secreted soluble factor(s) that increase RANKL-mediated osteoclastogenesis by around 20\%. However, Inoue et al. have reported that DU145 cells can significantly induce osteoclastogenesis through RANKL-dependent and -independent pathways [5]. The likely explanation of this discrepancy between their results and ours may be due to the different culture condition. In the present study, increased number of TRAP-positive multinucleated osteoclasts was observed in direct co-culture compared to separate co-culture using culture chamber. Different microenvironment caused by culture chamber in our system (i.e., fluid stress, $\mathrm{CO}_{2}$ supply etc, ) was suspected the reason for this discrepancy. Indeed, it has been reported that oscillatory fluid flow-induced shear stress modify RANKL/OPG ratio and resulted in a decrease in osteoclast formation [33]. Interestingly, it was able to observe that CM from DU145 cells significantly up-regulated MC3T3-E1 cell proliferation and activated ERK 1/2 and STAT3 signal transduction pathways without marked change in MC3T3-E1 cell 
differentiation. No marked effect of RANKL via RANK-positive DU145 cell on pre-osteoblast proliferation and osteoclastogenesis was observed. As suramin, a pan growth factor blocker, inhibited MC3T3-E1 cell proliferation induced by CM from DU145 cells, it can be suggested that DU145 cells produce more than one kind of growth factor that up-regulate MC3T3-E1 proliferation. Therefore, further studies are performed to identify the pre-osteoblast proliferation promoting factor(s) secreted by DU145 cells. The results of pre-osteoblastic cell proliferation assay with neutralizing inhibitors indicated that IL-6 secreted by DU145 cells has a partial role in DU145-induced MC3T3-E1 cell proliferation, however further studies are needed to identify other pre-osteoblast proliferation promoting factor(s) secreted by DU145 cells. IL-6 has long been considered as an osteoresorptive factor; however recent data indicate that IL-6 could influence osteoblastic cells, especially in the presence of soluble IL-6 receptor $[34,35]$. It has been reported that DU145 notably augmented the secretion of soluble IL-6 receptor in certain condition [36]. Interestingly, it has been reported that IL-6 contribute prostate cancer cell growth and IL-6 blockade achieved prostate cancer growth inhibition [37, 38]. Thus, IL-6 blockade is able to interfere with the vicious cycle in tumoral bone environment by not only induce prostate tumor regression, but also inhibit prostate cancer cell-induced pre-osteoblast cell proliferation.

Furthermore, it has been recently reported that CM from DU145 cells increases the local RANKL/OPG ratio by stimulating RANKL expression without any change in OPG's [5]. 
Thus DU145 cells may stimulate both osteoclast and RANK-positive prostate cancer cells in tumoral bone environment by increasing local RANKL expression, resulting in activation of the vicious cycle (Figure 8).

These findings are all consistent with a high trend of prostate cancer metastases to bone. Since Paget has suggested his "seed and soil" theory [39], the factors involved have been unknown for a long time. However, the unique anatomical structure of bone marrow vessels has been suggested to represent one of the factors that contribute to "seed" tumor cells into bone environment. A positive correlation has been reported between constant expressions of RANK with decreased/absent expression of RANKL and a high metastatic phenotype in breast carcinoma [40]. Taken together, we suggest that RANK-positive cells are starving RANKL and preferentially attracted by RANKL rich bone environment, where RANKL acts as a 'soil' factor that facilitates bone metastases development by activating both kinds of RANK-positive cells (osteoclast/osteoclast precursors and prostate cancer cells). However, further studies are needed to determine how RANKL is involved in the recruitment of RANK-positive tumor cells to bone environment.

In conclusion, the present study reveals the evidence that blocking RANKL-RANK interaction offer new therapeutic approach not only at the level of bone resorbing cells, but also by interfering with RANK-positive prostate cancer cells in the bone metastasis development. 


\section{Acknowledgements}

This work was supported by INSERM, The Région des Pays de la Loire and by a grant from the

West Committee of the Ligue Contre le Cancer. Kanji Mori received a personal fellowship

from the Ligue Nationale Contre le Cancer. 


\section{References}

1. Landis SH, Murray T, Bolden S, Wingo PA. Cancer statistics, 1999. CA Cancer J Clin 1999; 49: 8-31.

2. Mundy GR. Metastasis to bone: causes, consequences and therapeutic opportunities. Nat Rev Cancer 2002; 2: 584-93.

3. Clarke NW, McClure J, George NJ. Morphometric evidence for bone resorption and replacement in prostate cancer. Br J Urol 1991; 68: 74-80.

4. Garnero P, Buchs N, Zekri J, Rizzoli R, Coleman RE, Delmas PD. Markers of bone turnover for the management of patients with bone metastases from prostate cancer. Br J Cancer 2000; 82: 858-64.

5. Inoue H, Nishimura K, Oka D, Nakai Y, Shiba M, Tokizane T, Arai Y, Nakayama M, Shimizu K, Takaha N, Nonomura N, Okuyama A. Prostate cancer mediates osteoclastogenesis through two different pathways. Cancer Lett 2005; 223: 121-8. 
6. Zhang J, Dai J, Qi Y, Lin DL, Smith P, Strayhorn C, Mizokami A, Fu Z, Westman J, Keller ET. Osteoprotegerin inhibits prostate cancer-induced osteoclastogenesis and prevents prostate tumor growth in the bone. J Clin Invest 2001; 107: 1235-44.

7. Zhang J, Dai J, Yao Z, Lu Y, Dougall W, Keller ET. Soluble receptor activator of nuclear factor $\mathrm{kB}$ Fc diminishes prostate cancer progression in bone. Cancer Res 2003; 63: 7883-90.

8. Corey E, Brown LG, Kiefer JA, Quinn JE, Pitts TE, Blair JM, Vessella RL. Osteoprotegerin in prostate cancer bone metastasis. Cancer Res 2005; 65: 1710-8.

9. Whang PG, Schwarz EM, Gamradt SC, Dougall WC, Lieberman JR. The effects of RANK blockade and osteoclast depletion in a model of pure osteoblastic prostate cancer metastasis in bone. J Orthop Res 2005; 23: 1475-83.

10. Théoleyre S, Wittrant Y, Tat SK, Fortun Y, Rédini F, Heymann D. The molecular triad OPG/RANK/RANKL: involvement in the orchestration of pathophysiological bone remodeling. Cytokine Growth Factor Rev 2004; 15: 457-75. 
11. Hofbauer LC, Neubauer A, Heufelder AE. Receptor activator of nuclear factor-kappaB ligand and osteoprotegerin: potential implications for the pathogenesis and treatment of malignant bone diseases. Cancer 2001; 92: 460-70.

12. Kong YY, Yoshida H, Sarosi I, Tan HL, Timms E, Capparelli C, Morony S, Oliveira-dos-Santos AJ, Van G, Itie A, Khoo W, Wakeham A, Dunstan CR, Lacey DL, Mak TW, Boyle WJ, Penninger JM. OPGL is a key regulator of osteoclastogenesis, lymphocyte development and lymph-node organogenesis. Nature 1999; 397: 315-23.

13. Burgess TL, Qian Y, Kaufman S, Ring BD, Van G, Capparelli C, Kelley M, Hsu H, Boyle WJ, Dunstan CR, Hu S, Lacey DL. The ligand for osteoprotegerin (OPGL) directly activates mature osteoclasts. J Cell Biol 1999; 145: 327-38.

14. Lacey DL, Timms E, Tan HL, Kelley MJ, Dunstan CR, Burgess T, Elliott R, Colombero A, Elliott G, Scully S, Hsu H, Sullivan J, Hawkins N, Davy E, Capparelli C, Eli A, Qian YX, Kaufman S, Sarosi I, Shalhoub V, Senaldi G, Guo J, Delaney J, Boyle WJ. Osteoprotegerin ligand is a cytokine that regulates osteoclast differentiation and activation. Cell 1998; 93: $165-76$ 
15. Hsu H, Lacey DL, Dunstan CR, Solovyev I, Colombero A, Timms E, Tan HL, Elliott G, Kelley MJ, Sarosi I, Wang L, Xia XZ, Elliott R, Chiu L, Black T, Scully S, Capparelli C, Morony S, Shimamoto G, Bass MB, Boyle WJ. Tumor necrosis factor receptor family member RANK mediates osteoclast differentiation and activation induced by osteoprotegerin ligand. Proc Natl Acad Sci U S A 1999; 96: 3540-5.

16. Wittrant Y, Théoleyre S, Chipoy C, Padrines M, Blanchard F, Heymann D, Rédini F. RANKL/RANK/OPG: new therapeutic targets in bone tumors and associated osteolysis. Biochimica Biophysica Acta 2004; 1704: 49-57.

17. Brown JM, Corey E, Lee ZD, True LD, Yun TJ, Tondravi M, Vessella RL. Osteoprotegerin and rank ligand expression in prostate cancer. Urology 2001; 57: 611-6.

18. Brown JM, Vessella RL, Kostenuik PJ, Dunstan CR, Lange PH, Corey E. Serum osteoprotegerin levels are increased in patients with advanced prostate cancer. Clin Cancer Res 2001; 7: 2977-83.

19. Holen I, Croucher PI, Hamdy FC, Eaton CL. Osteoprotegerin (OPG) is a survival factor for human prostate cancer cells. Cancer Res 2002; 62: 1619-23. 
20. Nakagawa N, Kinosaki M, Yamaguchi K, Shima N, Yasuda H, Yano K, Morinaga T, Higashio K. RANK is the essential signaling receptor for osteoclast differentiation factor in osteoclastogenesis. Biochem Biophys Res Commun 1998; 253: 395-400.

21. Wittrant Y, Lamoureux F, Mori K, Riet A, Kamijo A, Heymann D, Rédini F. RANKL directly induces bone morphogenetic protein-2 expression in RANK-expressing POS-1 osteosarcoma cells. Int J Oncol 2006; 28: 261-9.

22. Tometsko M, Armstrong A, Miller R, Jones J, Chaisson M, Branstetter D, Dougall W. RANK Ligand directly induces osteoclastogenic, angiogenic, chemoattractive and invasive factors on RANK-expressing human cancer cells MDA-MB-231 and PC3. J Bone Miner Res 2004; 19: S25.

23. Chirgwin JM, Guise TA. Molecular mechanisms of tumor-bone interactions in osteolytic metastases. Crit Rev Eukaryot Gene Expr 2000; 10: 159-78.

24. Chirgwin JM, Mohammad KS, Guise TA. Tumor-bone cellular interactions in skeletal metastases. J Musculoskelet Neuronal Interact 2004; 4: 308-18. 
25. Guise TA, Chirgwin JM. Transforming growth factor-beta in osteolytic breast cancer bone metastases. Clin Orthop Relat Res 2003; 415 (suppl): S32-8.

26. Hansen MB, Nielsen SE, Berg K. Re-examination and further development of a precise and rapid dye method for measuring cell growth/cell kill. J Immunol Methods 1989; 119: 203-10.

27. Chipoy C, Berreur M, Couillaud S, Pradal G, Vallette F, Colombeix C, Rédini F, Heymann D, Blanchard F. Downregulation of osteoblast markers and induction of the glial fibrillary acidic protein by oncostatin $\mathrm{M}$ in osteosarcoma cells require PKCdelta and STAT3. J Bone Miner Res 2004; 19: 1850-61.

28. Fisher JL, Schmitt JF, Howard ML, Mackie PS, Choong PF, Risbridger GP. An in vivo model of prostate carcinoma growth and invasion in bone. Cell Tissue Res 2002; 307: 337-45.

29. Srivastava S, Matsuda M, Hou Z, Bailey JP, Kitazawa R, Herbst MP, Horseman ND. Receptor activator of NF-kappaB ligand induction via Jak2 and Stat5a in mammary epithelial cells. J Biol Chem 2003; 278: 46171-8. 
30. Jones DH, Nakashima T, Sanchez OH, Kozieradzki I, Komarova SV, Sarosi I, Morony S,

Rubin E, Sarao R, Hojilla CV, Komnenovic V, Kong YY, Schreiber M, Dixon SJ, Sims SM, Khokha R, Wada T, Penninger JM. Regulation of cancer cell migration and bone metastasis by RANKL. Nature 2006; 440: 692-6.

31. Lee ZH, Kim HH. Signal transduction by receptor activator of nuclear factor kappa B in osteoclasts. Biochem Biophys Res Commun 2003; 305: 211-4.

32. Guise TA. The vicious cycle of bone metastases. J Musculoskelet Neuronal Interact 2002; 2: $570-2$.

33. Kim CH, You L, Yellowley CE, Jacobs CR. Oscillatory fluid flow-induced shear stress decreases osteoclastogenesis through RANKL and OPG signaling. Bone 2006 Epub.

34. Kwan Tat S, Padrines M, Theoleyre S, Heymann D, Fortun Y. IL-6, RANKL, TNF-alpha/IL-1: interrelations in bone resorption pathophysiology. Cytokine Growth Factor Rev 2004; 15: 49-60. 
35. Franchimont N, Wertz S, Malaise M. Interleukin-6: An osteotropic factor influencing bone formation? Bone 2005; 37: 601-6.

36. Mori S, Murakami-Mori K, Bonavida B. Dexamethasone enhances expression of membrane and soluble interleukin- 6 receptors by prostate carcinoma cell lines. Anticancer Res 1998; 18: 4403-8.

37. Chung TD, Yu JJ, Spiotto MT, Bartkowski M, Simons JW. Characterization of the role of IL-6 in the progression of prostate cancer. Prostate 1999; 38: 199-207.

38. Smith PC, Hobisch A, Lin DL, Culig Z, Keller ET. Interleukin-6 and prostate cancer progression. Cytokine Growth Factor Rev 2001; 12: 33-40.

39. Paget S. The distrubution of secondary growths in cancer of the breast. Lancet $1889 ; 1$ : $571-2$.

40. Bhatia P, Sanders MM, Hansen MF. Expression of receptor activator of nuclear factor-kappaB is inversely correlated with metastatic phenotype in breast carcinoma. Clin Cancer Res 2005; 11: 162-5. 


\section{Figure legends}

Figure 1. Human prostate cancer cells DU145 and PC3 express OPG, RANK, IL-6 and

LIF at the transcriptional level. The expression of Receptor Activator of NF- $\kappa B$ Ligand (RANKL), RANK, osteoprotegerin (OPG), interleukin (IL)-6, IL-11, oncostatin M (OSM) and leukemia inhibitory factor (LIF) was analyzed in human prostate cancer cells DU145 and PC3 by semi-quantitative RT-PCR according to the condition described in the Materials and Methods section.

Figure 2. Immunodetection of RANK in human prostate cancer cell lines DU145 and PC3. Immunocytochemistry of RANK in DU145 (A) and PC3 (C) cells is represented together with respective negative controls $(\mathrm{B}, \mathrm{D})$. Original magnification: $\mathrm{x} 400$.

Figure 3. RANKL induces signal transduction pathways in RANK-positive DU145 and PC3 cells. At 70-80\% of confluence, DU145 and PC3 cells were serum starved for 24 hours, then incubated for the indicated times in the absence or presence of $100 \mathrm{ng} / \mathrm{ml}$ soluble human RANKL. Aliquots of whole cell lysates were analyzed by immunoblotting for phospho-ERK 1/2, p38 and Iא-B, and the corresponding total forms, as described in the Materials and Methods section. (A) DU145 cells, (B) PC3 cells. 
Figure 4. RANKL increases DU145 cell migration via the MEK/ERK pathway. (A) Treatment of DU145 cells with soluble human RANKL (shRANKL, 5, 100ng/ml) promoted cell invasion on the slit made in the DU145 confluent wells in a dose-dependent manner (a-c). The effects of human OPG (hOPG) alone or in association with shRANKL (shRANKL:hOPG ratio of 1:5) were studied following the same experimental condition (d, e). Several inhibitors of signal transduction pathways were tested in the same way [UO126, a MEK/ERK inhibitor $(10 \mu \mathrm{M})$; SB 203580, a p38 inhibitor $(10 \mu \mathrm{M})$ and SN 50, a NF- $\kappa \mathrm{B}$ translocation inhibitor $(18 \mu \mathrm{M})]$. Only UO126 partially inhibited RANKL-induced stimulation of DU145 cell migration (f, g). Treatment of PC3 cells with 100ng/ml shRANKL also promoted cell invasion on the slit made in the PC3 confluent well (h, i); however the magnitude was smaller than that of DU145. (B) Kinetic study of the RANKL-induced DU145 cell migration. The kinetic of DU145 cell invasion was quantified and compared in the absence and presence of $100 \mathrm{ng} / \mathrm{ml}$ shRANKL by slit time lapse assay. The results are the mean of total invaded areas of three distinct sections on the slit per 24 hours. *p=0.02, Mann-Whitney's $U$ test.

Figure 5. Soluble factor(s) secreted by DU145 cells promote osteoclastogenesis. Osteoclast precursors were generated from mouse bone marrow as described in the Materials and Methods section. They were incubated for 7 days in the absence or presence of DU145 cells $\left(10^{3}\right.$ cells for $10^{6}$ osteoclast precursors) in direct contact or separate condition using culture chambers in 
different soluble human RANKL concentrations (0-200ng/ml). *p $<0.05$ (with DU145 cells vs without DU145 cells), Mann-Whitney's $U$ test.

Figure 6. Conditioned medium from DU145 cells significantly up-regulates the MC3T3-E1 cell proliferation. (A) The mouse pre-osteoblast MC3T3-E1 cells were cultured for 72 hours in control conditioned medium (CT CM) or CM from DU145 cells in the presence or absence of $100 \mathrm{ng} / \mathrm{ml}$ soluble human RANKL as described in the Materials and Methods section. Cell proliferation was determined using a XTT based method. ${ }^{*} \mathrm{p}<0.001$ (CM from DU145 cells vs CT CM), Mann-Whitney's $U$ test. (B) The effect of suramin, a pan growth factor blocker was studied on MC3T3-E1 cell proliferation by trypan blue exclusion. **p $<0.001$ (CM from DU145 cells vs others), Mann-Whitney's $U$ test. CT CM: control conditioned medium, CM: CM from DU145 cells, S50: suramin 50 $\mu \mathrm{g} / \mathrm{ml}$, S100: suramin $100 \mu \mathrm{g} / \mathrm{ml}$. (C) Anti-mouse IL-6 receptor antibody $(10 \mu \mathrm{g} / \mathrm{ml})$ and anti-human LIF antibody $(10 \mu \mathrm{g} / \mathrm{ml})$ were tested as described in the Materials and Methods section. Anti-mouse IL-6 receptor antibody partially, but significantly abrogated DU145-induced MC3T3-E1 cell proliferation. $\uparrow \mathrm{p}=0.05$ (CM from DU145 cells with anti-mouse IL-6 receptor antibody vs other CM from DU145 group), Mann-Whitney's $U$ test. 
Figure 7. Soluble factor(s) secreted by DU145 cells induce phospho-ERK $1 / 2$ and phospho-STAT3 activation in MC3T3-E1 cells. At 70-80\% of confluence, MC3T3-E1 cells were washed three times with DMEM and cultured in serum-free DMEM for 24 hours, and then incubated for 30 minutes with control conditioned medium (CT CM). MC3T3-E1 cells were then incubated for 2, 5, 10, 15 and 30 minutes in the presence or absence of CM from DU145 cells. After the treatments, cell lysates were prepared as described in the Materials and Methods section and subjected to western blot analyses.

Figure 8. Schematic representation of the putative interactions between prostate cancer cells and osteoblastic/osteoclastic cells in tumoral bone microenvironment. RANK-positive prostate tumor cells preferentially target bone microenvironment where is rich in RANKL. In tumoral bone environment, RANKL produced by osteoblasts and bone stromal cells has two potential targets: osteoclast/osteoclast precursors and prostate cancer cells. RANKL acts as a 'soil' factor that facilitates prostate cancer metastasis development in bone by

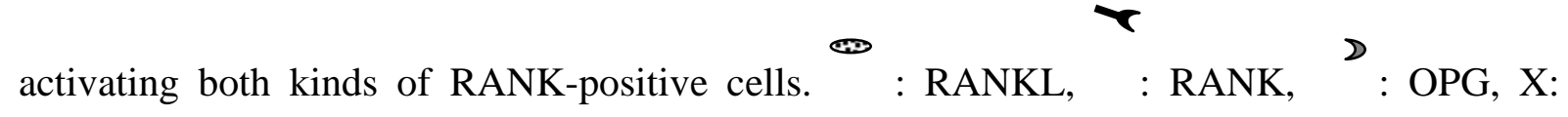
soluble factor(s) produced by prostate cancer cells. 


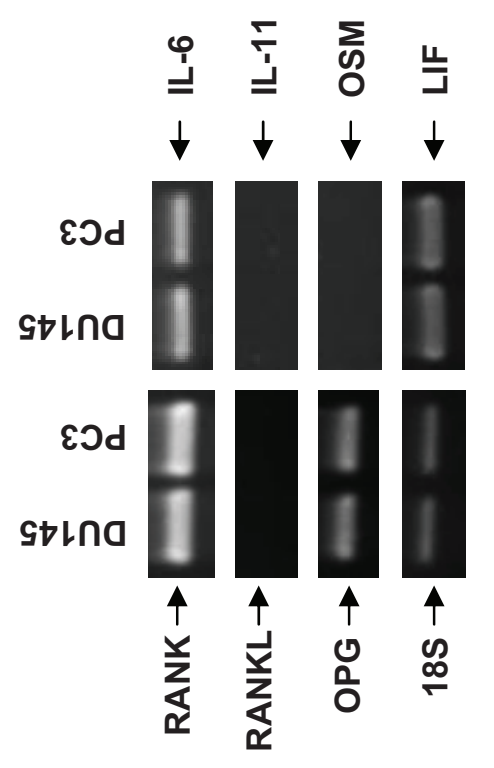

혼 


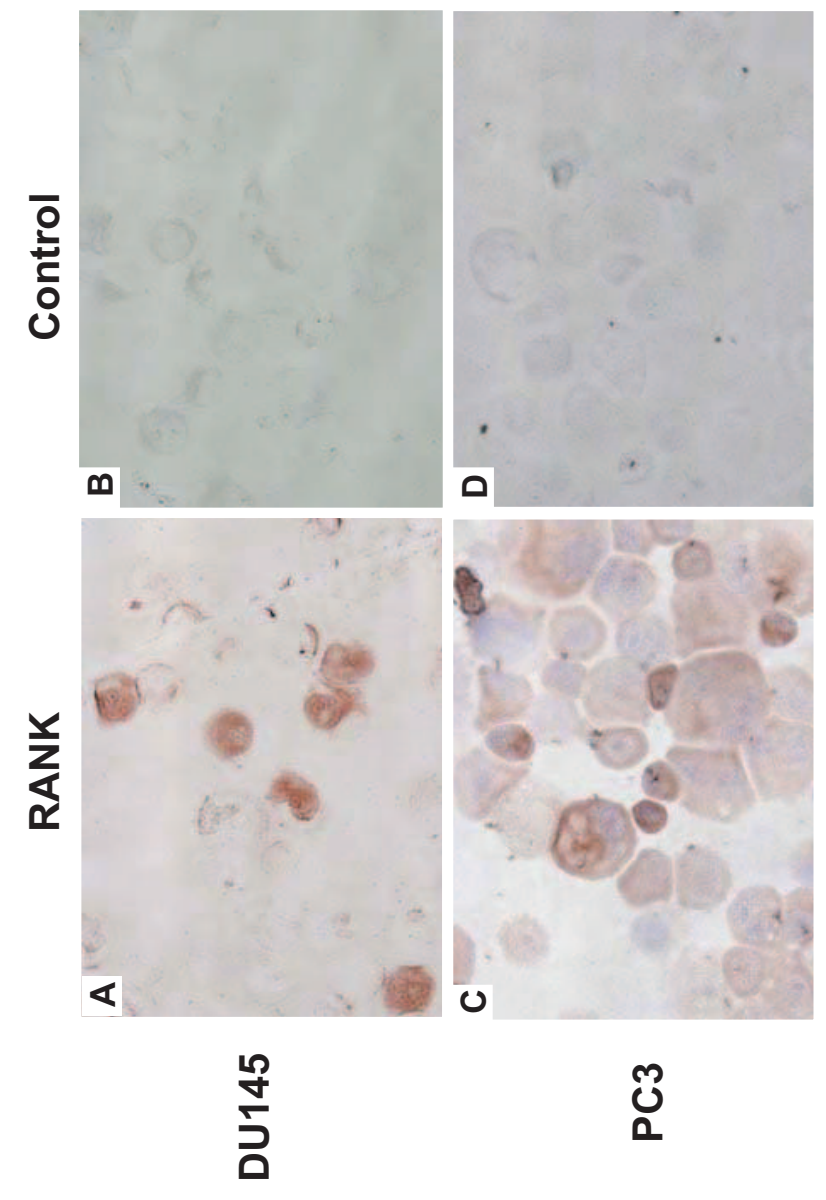

인 

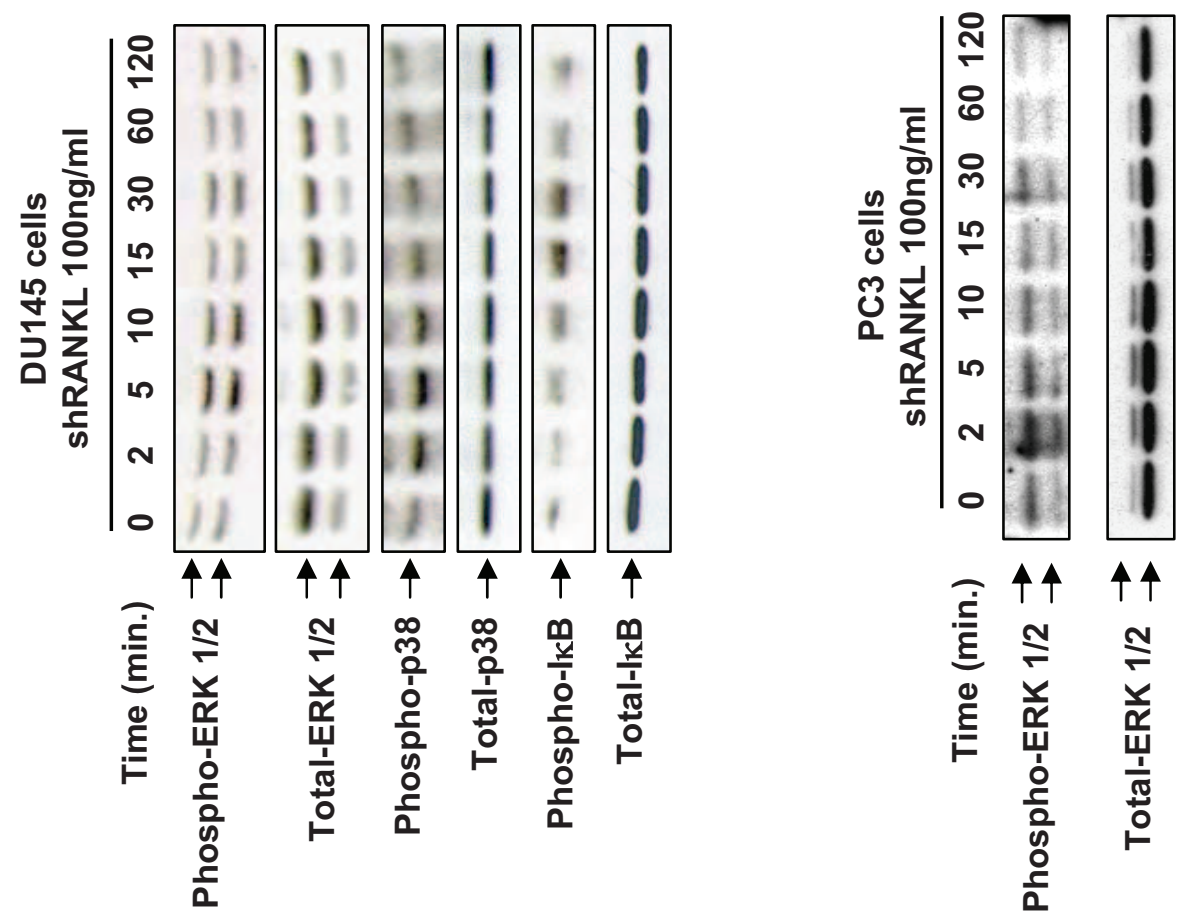

๕

$m$
m
$\frac{0}{3}$
운 

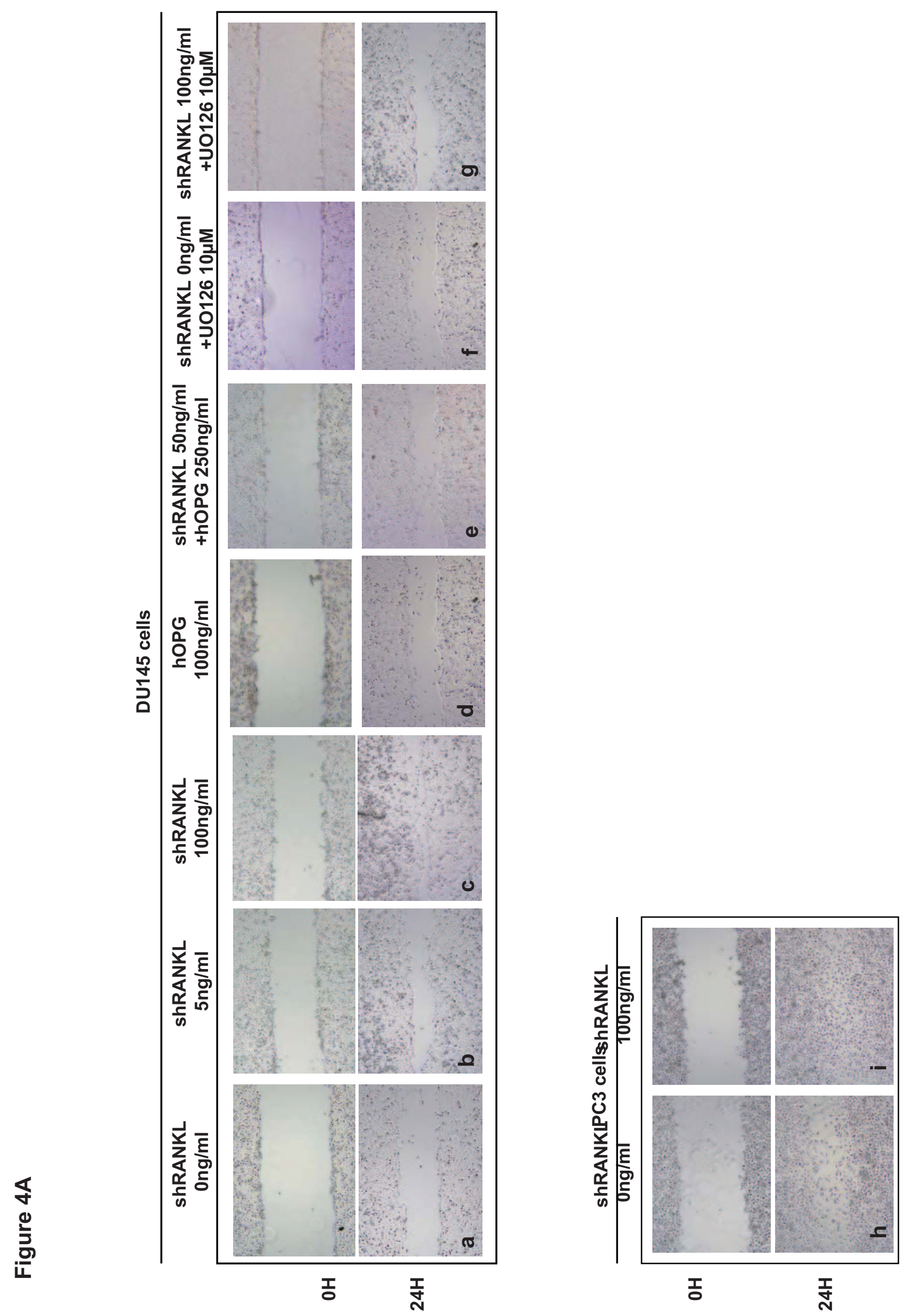


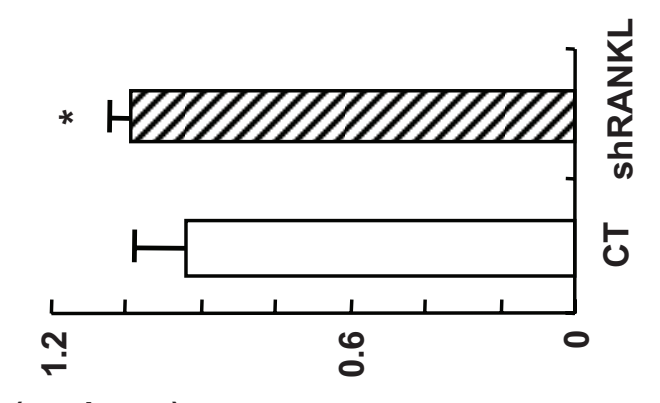

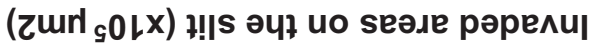

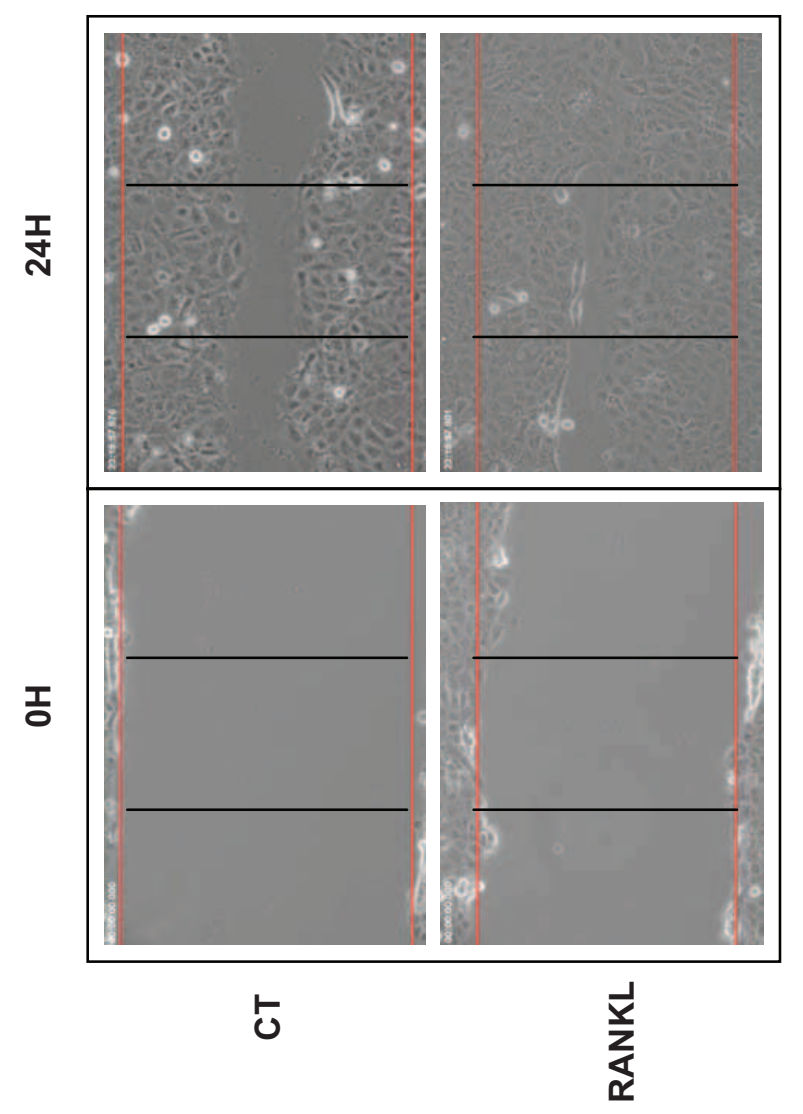

妾
인
은 


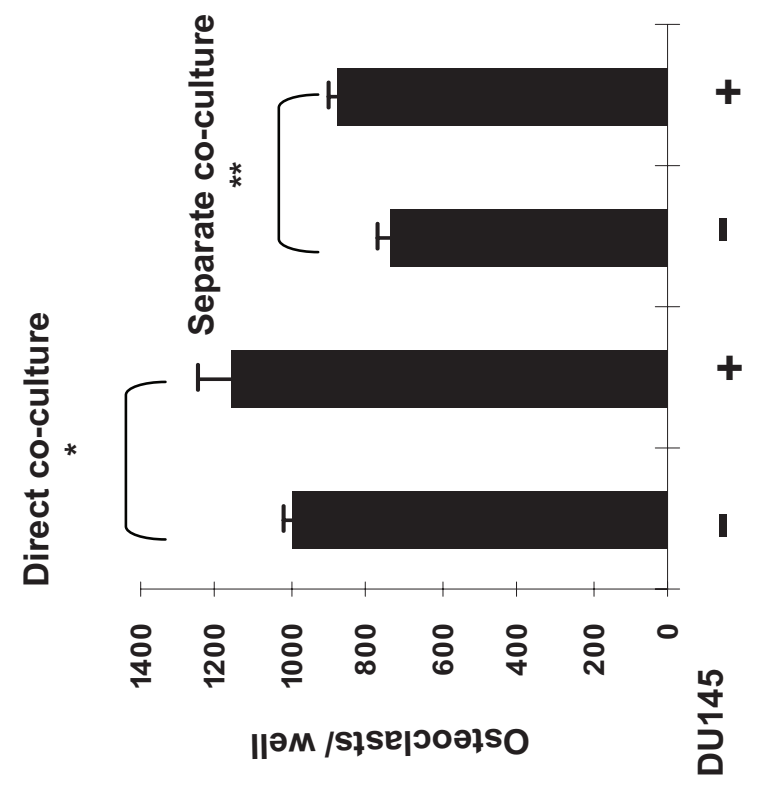

눈 

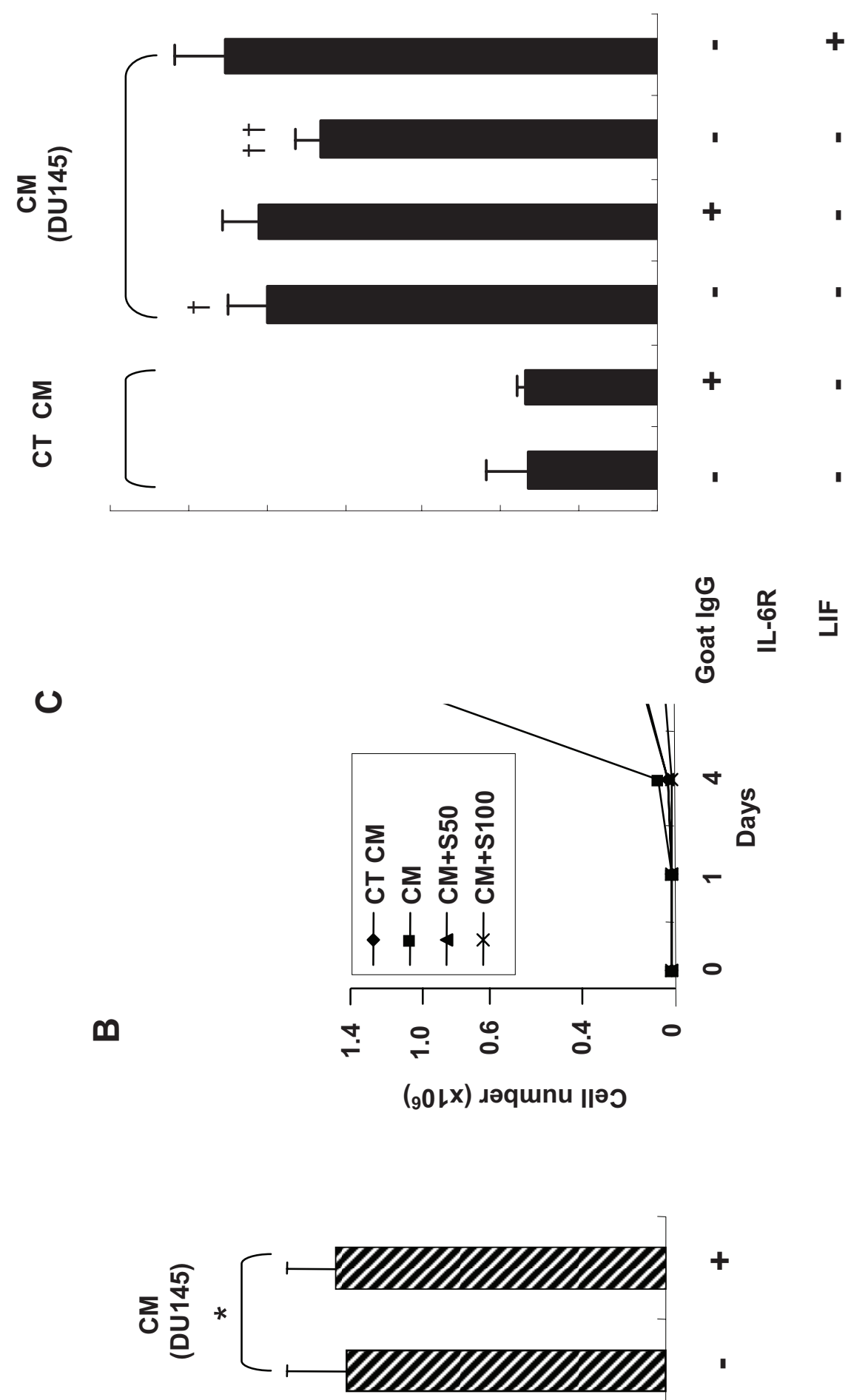

0
닌
은

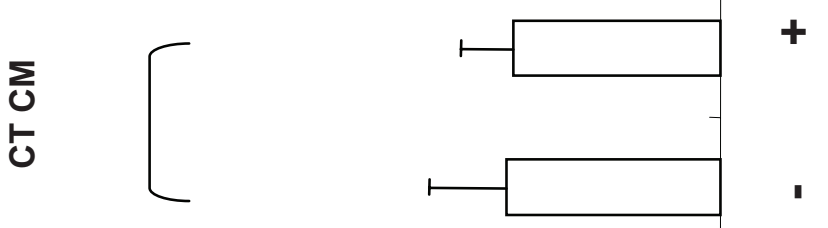

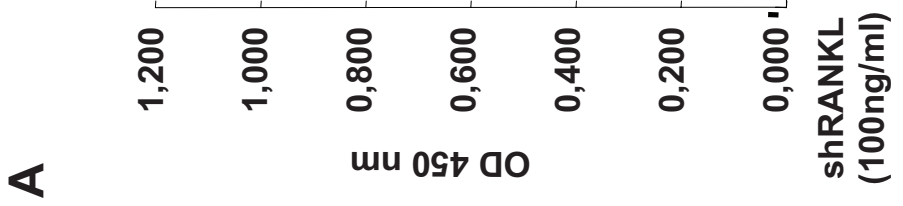




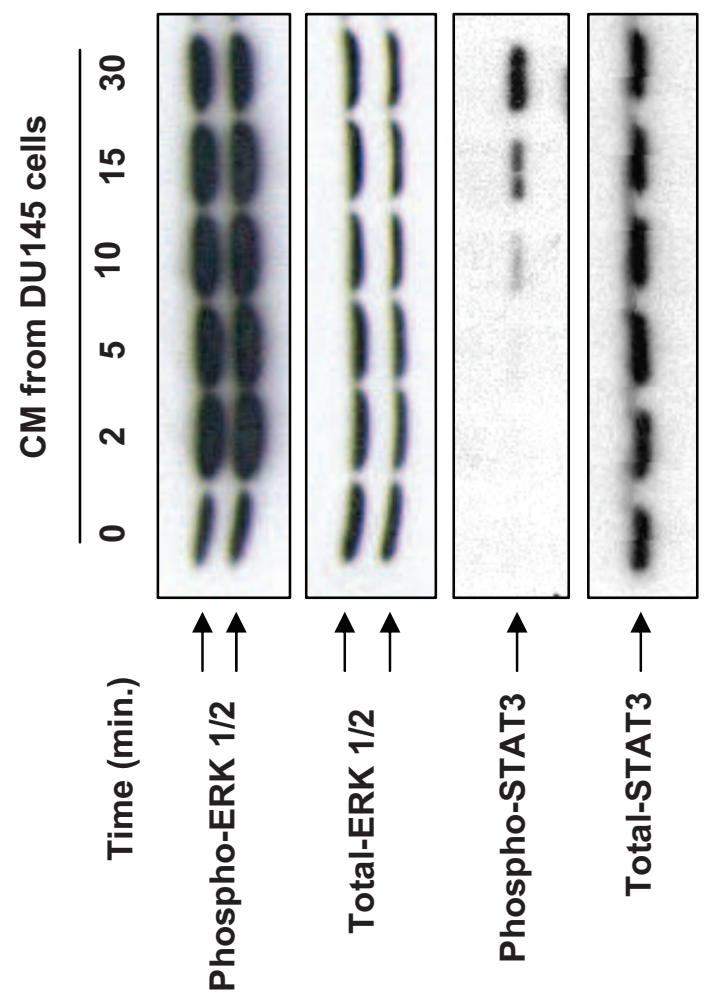

ํㅗㄴ 


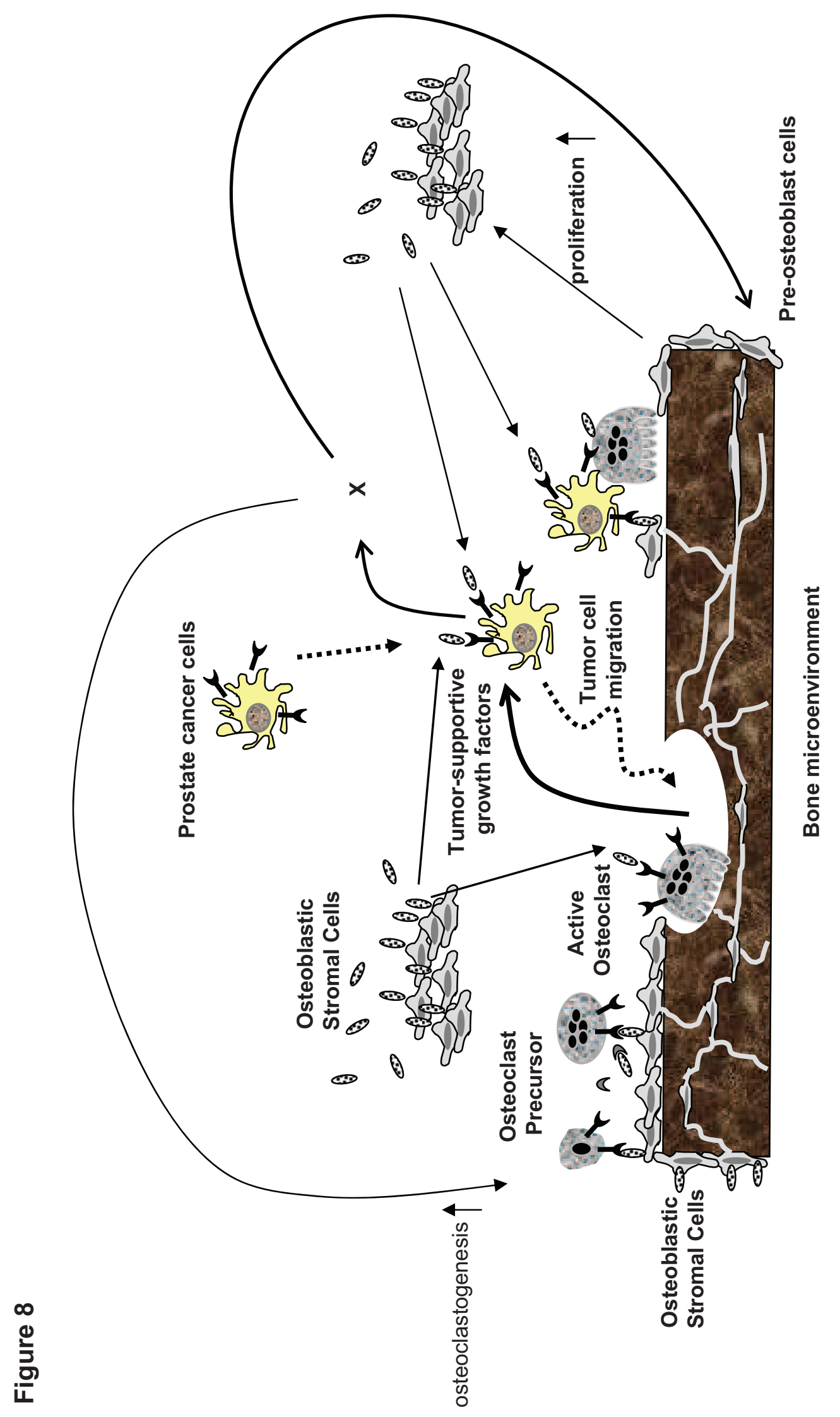

